\title{
Adjunctive misoprostol for prevention of post-partum haemorrhage: a pragmatic strategy of selective sequential administration
}

\author{
Nalini Mishra, Lalitha Priya Nekkanti*, Poulami Barma, Ishan Mishra
}

\author{
Department of Obstetrics and Gynecology, Pandit Jawaharlal Nehru Memorial Medical College, Raipur, Chhattisgarh, \\ India
}

Received: 13 December 2020

Accepted: 13 January 2021

\author{
*Correspondence: \\ Dr. Lalitha Priya Nekkanti, \\ E-mail: lalithanekkanti09@gmail.com
}

Copyright: (c) the author(s), publisher and licensee Medip Academy. This is an open-access article distributed under the terms of the Creative Commons Attribution Non-Commercial License, which permits unrestricted non-commercial use, distribution, and reproduction in any medium, provided the original work is properly cited.

\begin{abstract}
Background: To evaluate the effect of adjunctive misoprostol in preventing postpartum haemorrhage (PPH) by selective administration above threshold bleeding in order to reduce its side effects in comparison with primary prevention with oxytocin alone.

Methods: It was a prospective observational cohort study conducted at Government medical College of central India. Population included 500 low risk women delivering vaginally. After having received oxytocin as primary prevention, women were monitored for bleeding by quantitative assessment of blood loss (QBL) using an innovative drape (kept prepared at the point of care) and once bleeding crossed $350 \mathrm{ml}$ mark, alternate women were given $800 \mu \mathrm{g}$ misoprostol sublingually as an adjuvant (study group) and compared with those who did not receive adjuvant misoprostol (control group). Main outcome measure: Comparing the incidence of PPH and side effects between study and control group.

Results: 150 women had blood loss $>350 \mathrm{ml}$ which constituted 76 women in study and control group each. Incidence of PPH was significantly less in the study group (10.52 versus $22.36 \%, \mathrm{p}<0.05$, RR $0.47095 \% \mathrm{CI}=0.216-1.024)$. Though side effects were more $(38.15 \%)$ in study group but these were mild in nature and when the number was extrapolated to all recruited women, the incidence came down to $11.6 \%$.

Conclusions: Sequential adjuvant misoprostol at $350 \mathrm{ml}$ blood loss after primary prevention with oxytocin is an effective and pragmatic strategy for preventing PPH when compared to oxytocin alone but with reduced overall side effects owing to less number of women receiving misoprostol.
\end{abstract}

Keywords: Misoprostol, Oxytocin, PPH, C. G. Drape

\section{INTRODUCTION}

The Sustainable Development Goals has set new target of reducing the global maternal mortality ratio to less than 70 per 100000 live births by the year $2030 .^{1}$ Effective interventions to prevent PPH is critical to achieve this target as postpartum haemorrhage (PPH) still remains the leading direct cause of maternal mortality and morbidity in low and middle income countries (LMICs). ${ }^{2}$

The World Health Organization (WHO) took an important initiative in this direction by recommending the use of a uterotonic (particularly oxytocin, if available) as part of active management of third stage of labour
(AMTSL). Bringing down the mortality and morbidity due to PPH poses great challenge in the LMICs including India despite widespread use of oxytocin. One important identifiable gap here is maintenance of cold chain required by oxytocin to retain its full potency. A high prevalence of poor-quality oxytocin samples having inadequate amounts of active ingredient have been reported in LMICs. ${ }^{3-5}$

This problem justifies the need for an additional uterotonic in order to supplement oxytocin. Fortunately, a recent meta-analysis by Cochrane collaboration suggests that a combination of oxytocin plus misoprostol is probably superior to oxytocin alone. ${ }^{6}$ Subsequent to this, 
WHO has revised its recommendation in favour of the combination in case the additional benefit is regarded as important by the care provider and also emphasized the need of primary research pertaining to the most effective dose and route of administration of uterotonics for prevention of $\mathrm{PPH}^{7}$

Keeping these goals in view, the authors undertook the primary research aiming to strike a balance between the possible suboptimal quality of oxytocin and adverse effects of the misoprostol in a cost effective manner. We hypothesized that if instead of giving both the drugs for primary prevention to all the parturient, the use of adjunctive misoprostol is restricted, it can limit the cases who need misoprostol, thereby reducing the overall side effects.

To test our hypothesis, the present study was conducted to evaluate the impact of a pragmatic strategy to prevent PPH by adjunctive sublingual misoprostol after primary prevention with oxytocin (10 IU intramuscularly as per AMTSL), in the dose of $800 \mu \mathrm{g}$ after vaginal delivery at the warning threshold bleeding of $350 \mathrm{ml}$ (measured by specially designed drape prepared at the point of care) and to compare the outcome with those crossing the same threshold bleeding but without adjunctive misoprostol at a government medical college setting of central India.

\section{METHODS}

Present prospective observational cohort study was conducted in the government Medical College and associated Hospital of central India from November 2018 to April 2020 after obtaining clearance from the institutional ethical committees.

500 low risk gravid women admitted in the labor room having single live fetus presenting by vertex, at term and about to have vaginal delivery, were recruited in the study after obtaining informed consent and performing history taking, general and obstetric examination as well as reviewing of antenatal records with investigations.

Women having less than $8 \mathrm{gm}$ of haemoglobin, grandmultipara, preterm or post term pregnancy, premature rupture of membrane, intrauterine death of fetus, multiple pregnancy, malpresentation, high risk pregnancy with medical disorders like PE, heart disease, coagulation disorders, SCD, DM, severe anaemia, obstetric complication e.g. previous uterine surgeries (LSCS, myomectomy), antepartum haemorrhage (APH), Fibroid uterus, polyhydramnios, macrosomia, women under epidural analgesia, history of PPH in previous delivery, having known hypersensitivity to misoprostol, those needing operative vaginal delivery or caesarean section and PPH not due to atony were excluded from the study.

All women were monitored closely, findings were recorded and upon delivery of the baby, $10 \mathrm{IU}$ of oxytocin was given to all of them intramuscularly within one minute of birth, as per our departmental protocol.

Episiotomy was given if needed, and interval between incision and repair was noted. Time of birth and baby weight was recorded.

Quantitative assessment of blood loss (QBL) by combining the volumetric and gravimetric assessment was done objectively in real time in third stage of labour using C. G. Drape which was kept prepared beforehand at the point of care in the manner described (Figure 1). ${ }^{8}$ The drape was used for the direct assessment of blood loss. To this direct measurement, the gravimetric estimation was added which was derived by weighing the dressing pads with an electronic scale before and after being used to wipe blood during episiotomy repair, difference of each gram was taken as one $\mathrm{ml}$.

\section{G Drape for Blood loss estimation}

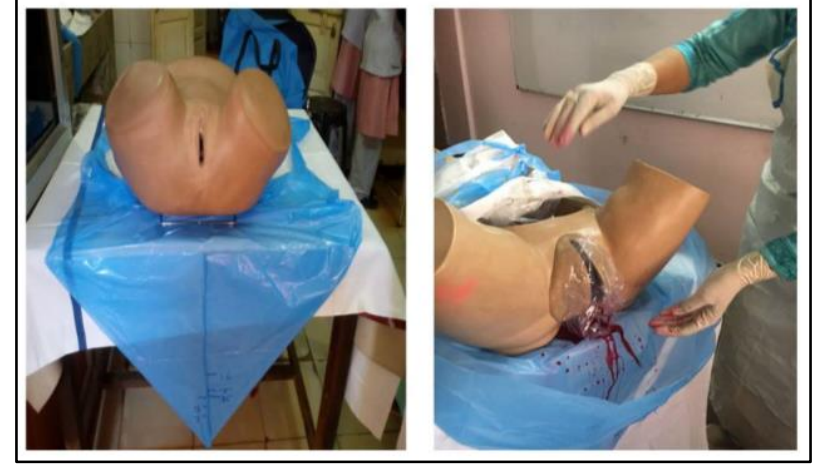

Figure 1: Innovative low cost drape for quantitative assessment of blood loss (QBL).

As soon as the QBL reached the threshold of $350 \mathrm{ml}, 800$ $\mu \mathrm{g}$ of misoprostol was given sublingually to alternate woman. Women receiving adjuvant dose of misoprostol constituted the study group whereas remaining women (with blood loss above $350 \mathrm{ml}$ ) who did not receive misoprostol were assigned to control group.

PPH was diagnosed if the QBL exceeded $500 \mathrm{ml}$ and immediate intervention started.

Blood loss was measured till bleeding controlled/up to 1 hour after delivery, whichever was later.

$\mathrm{Hb} \%$ was estimated at the time of recruitment before starting intravenous fluid as well as 24 and 48 hours after delivery

Primary outcome measure was the incidence of postpartum haemorrhage.

Secondary outcome measures were the need for additional uterotonic, blood transfusion, mean volumes of blood loss $(\mathrm{ml})$ and side effects of misoprostol like 
shivering, pyrexia (defined as temperature more than $98.4^{\circ} \mathrm{F}$ ) nausea, vomiting, diarrhoea or unpleasant taste.

Women were followed up to 48 hours of birth. Admission to intensive care unit or mortality was recorded if any.

\section{Statistical methods}

The data was collected in the prepared proforma and entered into Excel 2016 sheet and analysed with SPSS version 20. Results were reported as mean, SD or number percentage. Student's unpaired t test was used for analysis of continuous variables whereas the categorical variables were analyzed by Chi square test with $\mathrm{p}<0.05$ considered as significant. Relative risk (RR) and $95 \%$ confidence intervals $(95 \% \mathrm{CI})$ were calculated for categorical data.

\section{RESULTS}

Of the 500 women were recruited for QBL, 152 had blood loss $>350 \mathrm{ml}$. Of these, 76 women were given adjunct misoprostol (study group) whereas remaining 76 women were not (control group) (Figure 2, Consort chart).

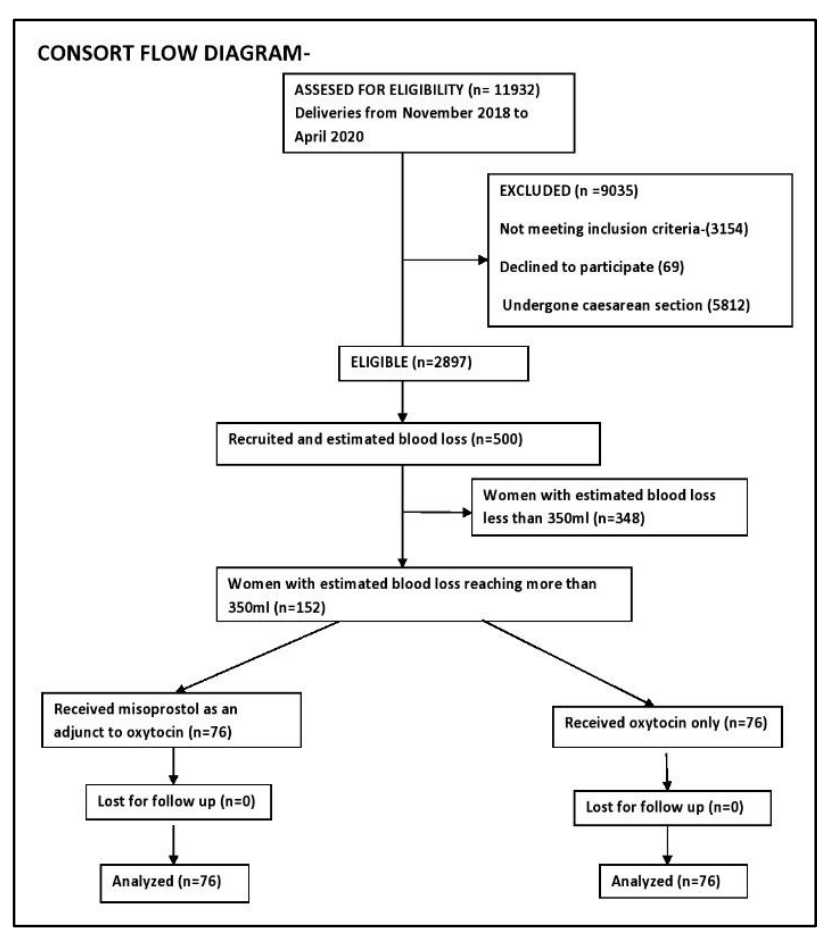

Figure 2: Consortium flow chart.

Table 1: Comparison of demographic and labour variables between the study and control groups.

\begin{tabular}{|llll|}
\hline $\begin{array}{l}\text { Variables } \\
\text { mean } \pm \text { SD }\end{array}$ & $\begin{array}{l}\text { Study group (misoprostol } \\
\text { adjunct to oxytocin })(\mathbf{n}=76)\end{array}$ & $\begin{array}{l}\text { Control group (oxytocin } \\
\text { only })(\mathbf{n}=76)\end{array}$ & P value \\
\hline Maternal age (years) & $24.1 \pm 3.7$ & $23.09 \pm 3.3$ & $\mathrm{NS}, \mathrm{p}=0.31$ \\
\hline Parity & $0.671 \pm 0.87$ & $0.684 \pm 0.89$ & $\mathrm{NS}, \mathrm{p}=0.43$ \\
\hline Gestational age(weeks) & $39.3 \pm 1.3$ & $39.2 \pm 1.2$ & $\mathrm{NS}, \mathrm{p}=0.319$ \\
\hline Weight $(\mathbf{k g})$ & $51.16 \pm 4.6$ & $51.54 \pm 5.2$ & $\mathrm{NS}, \mathrm{p}=0.25$ \\
\hline Height $(\mathbf{c m})$ & $149.92 \pm 5.09$ & $149.50 \pm 4.25$ & $\mathrm{NS}, \mathrm{p}=0.09$ \\
\hline Referred & $23(30.2)$ & $19(25)$ & $\mathrm{NS}, \mathrm{p}=0.46$ \\
\hline Rural residence & $25(32.8)$ & $16(21)$ & $\mathrm{NS}, \mathrm{p}=0.10$ \\
\hline Induction of labour & $16(21)$ & $20(26.3)$ & $\mathrm{NS}, \mathrm{p}=0.44$ \\
\hline History of PROM & $7(9.2)$ & $3(3.9)$ & $\mathrm{NS}, \mathrm{p}=0.19$ \\
\hline Duration of $\mathbf{1}^{\text {st }}$ stage of labor $($ hours) & $12.3 \pm 6.3$ & $11.9 \pm 5.3$ & $\mathrm{NS}, \mathrm{p}=0.45$ \\
\hline Duration of $\mathbf{2}^{\text {nd }}$ stage of labor $($ minutes) & $40.7 \pm 37.7$ & $42 \pm 32.6$ & $\mathrm{NS}, \mathrm{p}=0.32$ \\
\hline Duration of $\mathbf{3}^{\text {rd }}$ stage of labor $($ minutes) & $20 \pm 7.2$ & $20.3 \pm 6.6$ & $\mathrm{NS}, \mathrm{p}=0.23$ \\
\hline Episiotomy given & $55(72.3)$ & $65(85.5)$ & $\mathrm{NS}, \mathrm{p}=0.07$ \\
\hline Birth weight of baby $(\mathbf{k g})$ & $2.74 \pm 0.4$ & $2.73 \pm 0.36$ & $\mathrm{NS}, \mathrm{p}=0.66$ \\
\hline
\end{tabular}

$\mathrm{S}=$ Significant; NS=Not Significant

Table 1 shows that there was no significant difference between two groups with respect to age, parity, booking for antenatal care, gestational age, baseline haemoglobin before delivery, duration of labour, frequency of episiotomy, interval between incision and repair and birth weight of babies.

The outcome variables are shown in table two. The proportion of women with PPH (blood loss $>500 \mathrm{ml}$ ) was significantly less in the study group (10.52 versus $22.36 \%, \mathrm{p}<0.05$, RR $0.470,95 \% \quad \mathrm{CI}=0.216-1.024)$ (Figure 3) and translated to 118 fewer instances of PPH per 1000 women in the study group. Two women of control group had blood loss $>1000 \mathrm{ml}$ versus none in the study group and both cases responded well to medical management. The mean QBL was significantly less in the study group as well as the need for additional uterotonic agents (RR 0.44, 95\% CI, 0.205-0.959) (Figure 4) or 131 fewer per 1000 in the study group and mean decline in haemoglobin before and after delivery $(1.1 \pm 0.55$ versus $1.72 \pm 0.84, \mathrm{p}<0.0001)$ when compared to the control group. Though the number of blood transfusions were less in the study group (39 fewer per 1000), the difference was not significant statistically $(\mathrm{p}=0.348)$. 


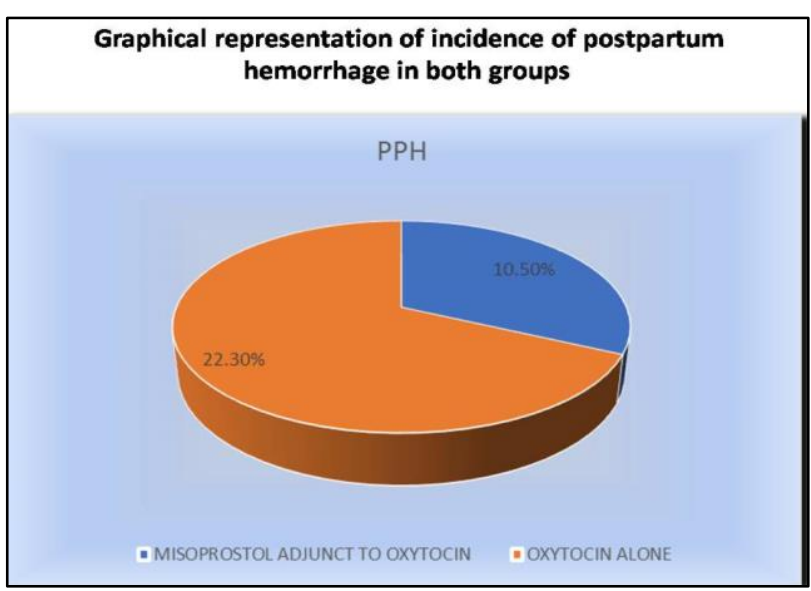

Figure 3: Primary outcome, the incidence of PPH.

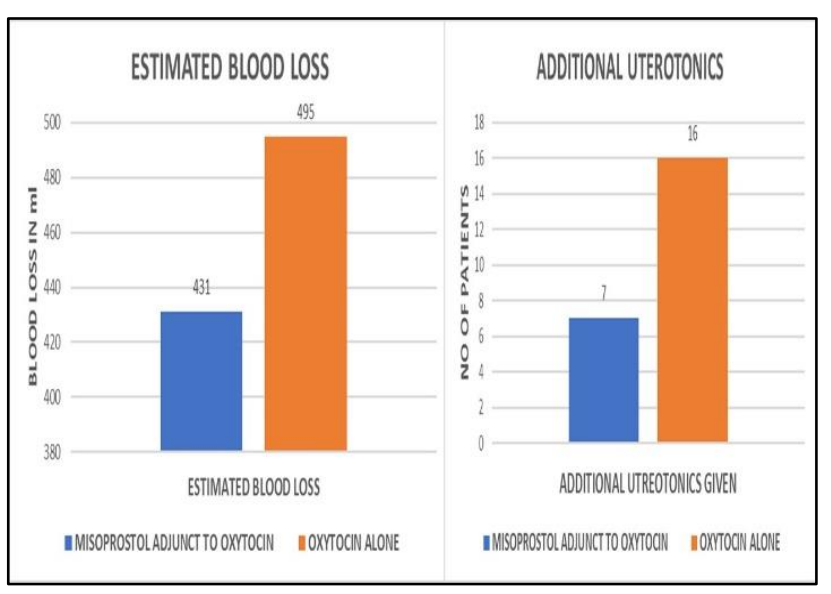

Figure 4: Graphic representation of mean blood loss and need of additional uterotonics.
Overall incidence of side effects was significantly higher in study group with 29 of $76(38.15 \%)$ women receiving adjuvant misoprostol. Shivering was the commonest side effect (Figure 5). Some of these women i.e. 12 (15\%) had transient fever too. Fever crossed $102^{\circ} \mathrm{F}$ in only one woman who needed medication. Nausea and vomiting usually lasted for 2-6 hours. There was no significant difference in incidence of vomiting. There was no incidence of diarrhoea.

In general the women did not complaint much about side effects unless asked about it and therefore these side effects were mostly detected during questionnaire while monitoring.

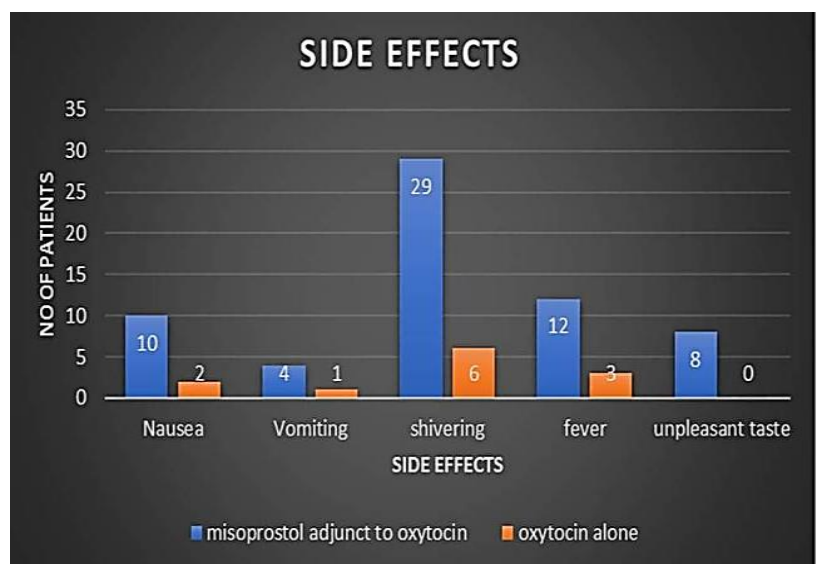

Figure 5: Side effects observed with administration of uterotonics for prevention of PPH.

There was no incidence of admission to intensive care unit or maternal death.

Table 2: Comparison of outcome variables between study and control group.

\begin{tabular}{|c|c|c|c|c|}
\hline Variables mean \pm SD & $\begin{array}{l}\text { Study group (misoprostol } \\
\text { adjunct to oxytocin) (n=76) }\end{array}$ & $\begin{array}{l}\text { Control group (oxytocin } \\
\text { only) }(n=76)\end{array}$ & $P$ value & RR $(95 \%$ CI $)$ \\
\hline PPH diagnosed & $8(10.52)$ & $17(22.36)$ & $S, p=0.048$ & $0.470(0.216-1.024)$ \\
\hline Estimated blood loss & $431.58 \pm 105.55$ & $495 \pm 132.79$ & $S, p=0.001$ & - \\
\hline Additional uterotonics & $8(10.52)$ & $18(23.68)$ & $S, p=0.031$ & $0.444(0.205-0.959)$ \\
\hline Blood transfusion & $4(5.26)$ & $7(9.21)$ & $\mathrm{NS}, \mathrm{p}=0.348$ & $0.571(0.174-1.872)$ \\
\hline Pre-delivery Hb (gm/dl) & $10.76 \pm 1.71$ & $10.94 \pm 1.38$ & $\mathrm{NS}, \mathrm{p}=0.481$ & \\
\hline Hb\% decline & $1.1 \pm 0.55$ & $1.72 \pm 0.84$ & $S, p<0.0001$ & \\
\hline Post-delivery Hb (gm/dl) & $9.6 \pm 1.12$ & $9.2 \pm 1.16$ & $\mathrm{~S}, \mathrm{p}=0.03$ & \\
\hline \multicolumn{5}{|l|}{ Side effects } \\
\hline Nausea & $10(13.16)$ & $2(2.63)$ & $\mathrm{S}, \mathrm{p}=0.016$ & $5.0(1.133-22.06)$ \\
\hline Vomiting & $4(5.26)$ & $1(1.32)$ & $\mathrm{NS}, \mathrm{p}=0.172$ & $4.0(0.457-34.96)$ \\
\hline Shivering & $29(38.15)$ & $6(7.89)$ & $S, p=0.00001$ & $4.83(2.12-16.56)$ \\
\hline Fever & $12(15.78)$ & $3(3.94)$ & $S, p=0.014$ & $4.0(1.175-13.61)$ \\
\hline Unpleasant taste & $8(10.52)$ & $0(0.0)$ & $S, p=0.016$ & $17.0(0.998-289.42)$ \\
\hline
\end{tabular}

S significant, NS Not significant, RR (Relative risk), 95\% CI( Confidence Interval) 
Table 3: Comparison of effect size between Cochrane meta-analysis, present study and World Health Organization in lieu of combination of oxytocin plus misoprostol over oxytocin alone.

\begin{tabular}{|c|c|c|c|c|c|}
\hline \multirow[t]{2}{*}{ Outcome } & \multicolumn{3}{|c|}{ Cochrane meta analysis ${ }^{6}$} & \multirow{2}{*}{$\begin{array}{l}\text { Present study } \\
\text { RR (95\% CI) }\end{array}$} & \multirow[t]{2}{*}{ WHO effect size ${ }^{7}$} \\
\hline & $\begin{array}{l}\text { No. of } \\
\text { studies }\end{array}$ & $\begin{array}{l}\text { No. of } \\
\text { participants }\end{array}$ & $\begin{array}{l}\text { Effect size } \\
\text { RR }(95 \% \text { CI })\end{array}$ & & \\
\hline PPH (>500 ml) & 14 & 8148 & $0.71(0.59-0.85)$ & $\begin{array}{l}0.470(0.21-1.024) \\
118 \text { fewer per } 1000\end{array}$ & 44 fewer per 1000 \\
\hline Additional uterotonics & 18 & 8391 & $0.54(0.44-0.67)$ & $\begin{array}{l}0.444(0.205-0.959) \\
131 \text { fewer per } 1000\end{array}$ & 58 fewer per 1000 \\
\hline $\begin{array}{l}\text { Mean difference in blood } \\
\text { loss }(\mathrm{ml})\end{array}$ & 17 & 8690 & $87.26(-157.83-16.69)$ & $\begin{array}{l}64 \mathrm{ml} \text { less on } \\
\text { average }\end{array}$ & $\begin{array}{l}88 \mathrm{ml} \text { less an } \\
\text { average }\end{array}$ \\
\hline Change in haemoglobin & 15 & 7929 & $-2.59(-3.70,-1.48)$ & & \\
\hline Blood transfusion & 19 & 8742 & $0.50(0.37,0.67)$ & $\begin{array}{l}0.571(0.174-1.872) \\
39 \text { fewer per } 1000\end{array}$ & 11 fewer per 1000 \\
\hline ICU admissions & 3 & 1886 & $0.50(0.05,5.47)$ & NA & \\
\hline Nausea & 7 & 3798 & $2.21(1.19,4.10)$ & $\begin{array}{l}5.0(1.133-22.06) \\
105 \text { more per } 1000\end{array}$ & 90 more per 1000 \\
\hline Vomiting & 11 & 6718 & $2.24(1.52,3.31)$ & $\begin{array}{l}4.0(0.457-34.96) \\
39 \text { more per } 1000\end{array}$ & 31 more per 1000 \\
\hline Shivering & 19 & 9458 & $3.38(2.50,4.57)$ & $\begin{array}{l}4.83(2.12-16.56) \\
355 \text { more per } 1000\end{array}$ & 238 more per 1000 \\
\hline Fever & 17 & 8607 & $2.99(2.00,4.45)$ & $\begin{array}{l}4.0(1.175-13.61) \\
118 \text { more per } 1000\end{array}$ & 62 more per 1000 \\
\hline
\end{tabular}

The results of present study were comparable with recent Cochrane meta-analysis and WHO in context of the effect size (Table 3).

\section{DISCUSSION}

The phrase "prevention is better than cure" is most appropriate in context of PPH, particularly in women of LMICs like ours, who are already anaemic. Prevention of $\mathrm{PPH}$ is the key practice to reduce maternal morbidity and mortality but reducing side effects is equally important and pragmatic approach of giving adjunct misoprostol to only those above warning haemorrhage has shown significantly less incidence of PPH in the study group (10.52 versus $22.36 \%, \mathrm{p}<0.05$, RR $0.47095 \% \mathrm{CI}=0.216$ 1.024, 118 fewer instances of PPH per 1000 women). There was a significant reduction in the need of additional uterotonics and mean decline in haemoglobin before and after delivery in the study group.

Though the side effects of misoprostol were significantly higher in the study group, the total number of women suffering were 29 out of 76 belonging to study group and if this figure is extrapolated to control group as well then the estimated number would have been 58 out of 152 women who bled $>350 \mathrm{~mL}$ but then it would have prevented additional $11 \%$ cases of $\mathrm{PPH}$ while limiting the number of women exposed to misoprostol to same (58 in 500) women initially recruited, that would translate the incidence of side effect into $11.6 \%$ only which is a reasonable bargain to reduce $\mathrm{PPH}$ and associated morbidities.
Limiting the number of cases being given adjunct misoprostol has limited the side effects in overall cohort of parturient.

Though primary prevention with oxytocin is being practiced widely, it is not always effective and the need of additional or adjuvant uterotonics is reported to be 10 $40 \% .{ }^{9,10}$

The logic pertaining to the choice of adjuvant utertonic, timing, dose and route used in the present study was in accordance to recent evidence while formulating an innovative approach of using administration of adjunct misoprostol in selective group of parturient as discussed below:

While choosing the drug for adjudication, it was found that Cochrane collaboration reported high-certainty evidence that misoprostol plus oxytocin combination reduces the need for additional uterotonic agents compared to oxytocin alone. ${ }^{6}$ Subsequently WHO have acknowledged three better effective drugs/ combinations for prevention of $\mathrm{PPH} \geq 500 \mathrm{ml}$ namely carbetocin, ergometrine plus oxytocin and misoprostol plus oxytocin combination compared with oxytocin alone. ${ }^{7}$ Out of these, carbetocin is not available in LMICs. The ergometrine plus oxytocin combination use is again complicated by doubtful potency of drug owing to inadequate cold chain as well as availability. ${ }^{3-5}$

Misoprostol plus oxytocin combination was chosen in the present study as misoprostol is widely available, cheap, stable at room temperature and has the ease of 
administration. The efficacy of misoprostol alone as well as an adjunct to oxytocin for prevention of PPH is well documented. $^{9-20}$ In contrast very few studies have reported a contrary view but have used a lower dose. ${ }^{21}$ Choosing the optimal dose is imperative to achieve the goal as discussed later.

The timing of adjudication was based on our proposed policy of administering misoprostol in a sequential manner for secondary prevention at the threshold of QBL of $350 \mathrm{ml}$ and not exposing every woman to the combination of oxytocin and misoprostol which differs from previous studies. This endeavour was carried out to limit the number of women exposed to misoprostol and thereby limit the overall side effects while gaining the benefit at the time crucial for prevention of PPH. The side effects of misoprostol have been a cause of caution and concern. ${ }^{6,7}$ In this way we could limit the total women needing adjuvant misoprostol to 152 instead of all 500 . Out of these, $50 \%$ (76) of the women were given misoprostol.

The logic behind choosing this threshold volume is that in lieu of incidence of anaemia in pregnant women of LMICs, $350 \mathrm{ml}$ is a clear warning of PPH and secondary prevention is needed urgently. At this juncture, the accurate measurement of blood loss is imperative. In our study, utmost care was taken for QBL done with the help of a specially designed drape prepared in our own facility using a plastic apron inside the safe delivery kit supplied by the government (Figure 1). The plastic apron may also be procured from the market and is very cheap (around $0.2 \$$ or 15 rupees approximately). ${ }^{8}$ It is soft and can be kept folded under the labouring woman's buttocks before cutting the cord so that mixing of blood with amniotic fluid is avoided enabling accurate measurement of actual blood loss.

Secondary prevention of postpartum haemorrhage with misoprostol has been found to be non-inferior to universal prophylaxis for PPH when given by the sublingual route. ${ }^{22}$ The drug has its onset of action in 11 min with duration of action being 3 hours through sublingual route and was chosen owing to ease of administration, fastest absorption by avoidance of the first pass metabolism, rapid onset of action and highest serum levels. Fast and high levels of the drug are urgently needed once the woman has already lost $350 \mathrm{ml}$ of blood and the threat of $\mathrm{PPH}$ is looming large. Sublingual misoprostol is reported to have minimal adverse effects. ${ }^{23}$

The decision regarding the dose of misoprostol was based upon the urgent need of fast and best effective dose at the threshold of $350 \mathrm{ml}$ of blood loss. On reviewing the studies in context of dose, it was found that those reporting no additional benefit of misoprostol as an adjunct have used the dose of $\leq 600 \mu \mathrm{g} .{ }^{21}$ When comparing various doses in a single study, $800 \mu \mathrm{g}$ was found to be most effective without much difference in terms of side effects. ${ }^{24} \mathrm{We}$ chose a dose of $800 \mu \mathrm{g}$ to be sure of its efficacy. The same dose and route is also recommended by FIGO for secondary prevention of PPH. ${ }^{25}$ Though this recommendation is for facilities not having injectable uterotonics but one has to consider that even when the oxytocin has already been used as a primary preventive tool, its potency is rendered questionable due to the storage conditions of LMICs. For the same excuse, it is recommended in LMICs even by those who advocate against its use in high income countries. $^{21}$

Our finding of statistically significant reduction of incidence of PPH, mean blood loss, use of additional uterotonic and haemoglobin decline in the study group when compared to control group has amply reflected the efficacy of our regime. The results of present study is in accordance with the observations already made by top world authorities. 6,7

The adverse effects however were mostly self-limiting and none was life threatening.

The benefits of this pragmatic policy clearly outweigh the disadvantages in terms of side effects. The simplicity and sustainability of this cost effective and user friendly approach may be a boon for LMICs in order to prevent PPH.

Limitation of this study is not being a randomized control trial.

\section{CONCLUSION}

In summary, the present study makes an important observation that adjuvant sublingual misoprostol when given to selected set of women as a secondary tool subsequent to blood loss of $350 \mathrm{ml}$ after vaginal delivery in low risk gravid women who already had primary prevention with oxytocin, effectively reduces incidence of post-partum haemorrhage, mean blood loss, need of additional uterotonics and mean haemoglobin decline in significant proportions but at the same limits the number of women exposed to adjuvant misoprostol and thereby limits the overall side effects of misoprostol.

Funding: No funding sources

Conflict of interest: None declared

Ethical approval: The study was approved by the Institutional Ethics Committee

\section{REFERENCES}

1. UN. Sustainable Development Goals: 17 Goals to Transform our World. United Nations. 2015. Available from: https://www.un.org/en/exhibits/ page/sdgs-17-goals-transform-world. Accessed on 14 October 2020.

2. Global, regional, and national age-sex specific mortality for 282 causes of death in 195 countries and territories, 1980-2017: a systematic analysis for 
the Global Burden of Disease Study 2017. Lancet. 2018;392(10159):1736-88.

3. Torloni MR, Gomes Freitas C, Kartoglu UH, Metin G€ulmezoglu A, Widmer M. Quality of oxytocin available in low- and middleincome, countries: a systematic review of the literature. BJOG. 2016;123:2076-86.

4. Oliver VL, Lambert PA, Than KK, Mohamed Y, Luchters S, Verma S, et al. Knowledge, perception and practice towards oxytocin stability and quality: A qualitative study of stakeholders in three resourcelimited countries. PLoS One. 2018;13(9): e0203810.

5. Indrayani I, Harianis S, Astuti H, Maria R. How is oxytocin cold chain in peripheral areas? And is it still effective uterotonic? Pak J Med Health Sci. 2018;12(4):1744-9.

6. Gallos ID, Papadopoulou A, Man R, Athanasopoulos N, Tobias A, Price MJ, Williams MJ, Diaz V, Pasquale J, Chamillard M, Widmer M. Uterotonic agents for preventing postpartum haemorrhage: a network meta-analysis. Cochrane Database Syst Rev. 2018(12).

7. WHO recommendations: uterotonics for the prevention of postpartum haemorrhage. Geneva: World Health Organization; 2018. Available from: https://apps.who.int/iris/bitstream/handle/10665/2772 76/9789241550420-eng.pdf?ua $=1$. Accessed on 14 October 2020.

8. Mishra N, Baghel M, Gupta A, Shrivastava S, Chandrawanshi H. Use of Innovative low cost drape for assessment of blood loss during delivery: A report. J South Asian Fed Obstet Gynaecol 2019;11(1):30-4.

9. Sitaula S, Uprety DK, Thakur A, Pradhan T. Impact of preoperative rectal misoprostol on blood loss during, and after elective cesarean delivery: a randomized controlled trial. Nepal J Obstet Gynecol. 2016;22(2):37-41.

10. Hernandez-Castro F, Lopez-Serna N, TrevinoSalinas EM, Soria-Lopez JA, Sordia-Hernandez LH, Cardenas-Estrada E. Randomized double-blind placebo-controlled trial of buccal misoprostol to reduce the need for additional uterotonic drugs during cesarean delivery. Int $\mathbf{J}$ Gynaecol Obstet. 2016;132(2):184-7.

11. Perez-Rumbos A, Reyna-Villasmil E Rondon-Tapia M, Reyna Villasmil N. Rectal misoprostol or intramuscular oxytocin in the management of the third phase of labour. Perinatología y Reproducción Humana 2017;31(2):78-84.

12. Sallam HF, Shady NW. Adjunctive sublingual misoprostol for secondary prevention of post-partum hemorrhage during cesarean delivery: double blind placebo randomized controlled trial. Int J Reprod Contracept Obstet Gynecol. 2018;7(2):495-502.

13. Asmat R, Ashraf T, Asmat F, Asmat S, Asmat N. Effectiveness of per rectal misoprostol versus intramuscular oxytocin for prevention of primary postpartum haemorrhage. J Coll Phys Surg Pak. 2017;27(1):13-7.

14. Diallo M, Sylla T, Diouf AA, Moreira PM, Gassama $\mathrm{O}$, Gueye MD, et al. Active management of third stage of labour with low doses of oral misoprostol and oxytocin on low: risk parturient in a Sub-Saharan hospital, Dakar, Sénégal. Int J Reprod Contracept Obstet Gynecol. 2017;6(2):516-22.

15. Shady NW, Sallam HF, Elsayed AH, Abdelkader AM, Ali SS, Alanwar A, et al. The effect of prophylactic oral tranexamic acid plus buccal misoprostol on blood loss after vaginal delivery: a randomized controlled trial. J Matern Fet Neonat Med. 2017;27:1-7.

16. Gavilanes $\mathrm{P}$, Morales MF, Velasco S, Teran E. Sublingual misoprostol is as effective as intravenous oxytocin to reduce intra-operative blood loss during cesarean delivery in women living at high altitude. J Matern Fet Neonat Med. 2016;29(4):559-61.

17. Othman ER, Fayez MF, El Aal DEMA, El-Dine Mohamed HS, Abbas AM, Ali MK. Sublingual misoprostol versus intravenous oxytocin in reducing bleeding during and after caesarean delivery: a randomized clinical trial. Taiwanese $\mathbf{J}$ Obstet Gynecol. 2016;55(6):791-5.

18. Chaudhuri P, Majumdar A. A randomized trial of sublingual misoprostol to augment routine thirdstage management among women at risk of postpartum hemorrhage. Int $\mathbf{J}$ Gynecol Obstet. 2016;132:191-5.

19. Morfaw F, Fundoh M, Pisoh C, Ayaba B, Mbuagbaw L, AndersonL N, Thabane L. misoprostol as an adjunct to oxytocin can reduce postpartumhaemorrhage: a propensity score-matched retrospective chart review in Bamenda-Cameroon, 2015-2016. BMC Pregnanc Childbirth. 2019;19:257.

20. Chaudhuri P, Majumdar A. Sublingual misoprostol as an adjunct to oxytocin during cesarean delivery in women at risk of postpartum hemorrhage. Int $\mathbf{J}$ Gynecol Obstet. 2015;128:48-52.

21. Quibel T, Ghout I, Goffinet F, Salomon LJ, Fort J, Javoise $S$, et al. Active management of the third stage of labor with a combination of oxytocin and misoprostol to prevent postpartum hemorrhage: a randomized controlled trial. Obstet Gynecol. 2016;128 (4):805-11.

22. Raghavan S, Geller S, Miller S, Goudar SS, Anger H. Misoprostol for primary versus secondary prevention of postpartum haemorrhage: a clusterrandomised non-inferiority community trial BJOG. 2016;123:120-7.

23. Pakniat H, Khezri MB. The effect of combined oxytocin-misoprostol versus oxytocin and misoprostol alone in reducing blood loss at cesarean delivery: a prospective randomized double-blind study. J Obstet Gynecol India. 2015;65(6):376-81.

24. Uncu Y, Karahasan M, Uyaniklar Ö, Uncu G. Prophylactic misoprostol for the prevention of 
postpartum hemorrhage: a randomized controlled trial. Eur Revi Med Pharm Sci. 2015;19:15-22.

25. Morris JL, Winikoff B, Dabash R, Weeks A, Faundes A, Gemzell-Danielsson K, et al. FIGO's updated recommendations for misoprostol used alone in gynecology and obstetrics. Int J Gynecol Obstet. 2017;138:363-6.

Cite this article as: Mishra N, Nekkanti LP, Barma P, Mishra I. Adjunctive misoprostol for prevention of post-partum haemorrhage: a pragmatic strategy of selective sequential administration. Int J Reprod Contracept Obstet Gynecol 2021;10:669-76. 